\title{
At Immature Mossy-Fiber-CA3 Synapses, Correlated Presynaptic and Postsynaptic Activity Persistently Enhances GABA Release and Network Excitability via BDNF and cAMP-Dependent PKA
}

\author{
Sudhir Sivakumaran, Majid H. Mohajerani, and Enrico Cherubini \\ Neuroscience Programme, International School for Advanced Studies, 34014 Trieste, Italy
}

In the adult rat hippocampus, the axons of granule cells in the dentate gyrus, the mossy fibers (MF), form excitatory glutamatergic synapses with CA3 principal cells. In neonates, MF release into their targets mainly GABA, which at this developmental stage is depolarizing. Here we tested the hypothesis that, at immature MF-CA3 synapses, correlated presynaptic [single fiber-evoked $\mathrm{GABA}_{\mathrm{A}}$-mediated postsynaptic potentials (GPSPs)] and postsynaptic activity (back propagating action potentials) may exert a critical control on synaptic efficacy. This form of plasticity, called spike-timing-dependent plasticity (STDP), is a Hebbian type form of learning extensively studied at the level of glutamatergic synapses. Depending on the relative timing, pairing postsynaptic spiking and single MF-GPSPs induced bidirectional changes in synaptic efficacy. In case of positive pairing, spike-timing-dependent-long-term potentiation (STD-LTP) was associated with a persistent increase in GPSP slope and in the probability of cell firing. The transduction pathway involved a rise of calcium in the postsynaptic cell and the combined activity of cAMP-dependent PKA (protein kinase A) and brain-derived neurotrophic factor (BDNF). Retrograde signaling via BDNF and presynaptic TrkB receptors led to a persistent increase in GABA release. In "presynaptically" silent neurons, the enhanced probability of GABA release induced by the pairing protocol, unsilenced these synapses. Shifting $\mathrm{E}_{\mathrm{GABA}}$ from the depolarizing to the hyperpolarizing direction with bumetanide failed to modify synaptic strength. Thus, STD-LTP of GPSPs provides a reliable way to convey information from granule cells to the CA3 associative network at a time when glutamatergic synapses are still poorly developed.

Key words: hippocampal mossy fibres; excitatory action of GABA; spike-timing-dependent plasticity; increased synaptic efficacy; BDNF; cAMP-dependent PKA

\section{Introduction}

Spike-timing-dependent plasticity (STDP) is a particular form of associative Hebbian type of learning, crucial for information coding. STDP consists in a bidirectional modification of synaptic strength which relies on the temporal order of presynaptic and postsynaptic spiking (Dan and Poo, 2006). Thus, positively correlated presynaptic and postsynaptic spiking (pre before post) within a critical window leads to long-term potentiation (LTP), whereas a negative correlation (post before pre) induces longterm depression (LTD) (Markram et al., 1997; Bi and Poo, 1998; Debanne et al., 1998; Feldman, 2000) (for review, see Dan and Poo, 2006). While at glutamatergic synapses STDP has been extensively studied (Dan and Poo, 2004, 2006; Caporale and Dan,

Received 0ct. 17, 2008; revised Jan. 17, 2009; accepted Jan. 19, 2009.

This work was supported by Ministero Istruzione Universita' e Ricerca (Grant MIUR-PRIN 2005) and European Union Grant 503221 to E.C. We are grateful to Delma Caiati for participating in some experiments.

Correspondence should be addressed to Enrico Cherubini, Neurobiology Sector, International School of Advanced Studies (SISSA), Ed. Q1 Area Science Park, S.S.14 Km 163.5, 34012 Basovizza (Trieste), Italy. E-mail: cher@sissa.it.

M. H. Mohajerani's present address: Department of Psychiatry, University of British Columbia, Vancouver, British Columbia, Canada V6T 1 Z3.

DOI:10.1523/JNEUROSCI.5019-08.2009

Copyright $\odot 2009$ Society for Neuroscience $\quad$ 0270-6474/09/292637-11\$15.00/0
2008), at GABAergic connections the information available is limited (Caporale and Dan, 2008). In the hippocampus of juvenile animals, correlated spiking activity has been shown to induce a downregulation of the $\mathrm{K}^{+}-\mathrm{Cl}^{-}$cotransporter KCC2 with consequent increase in $\left[\mathrm{Cl}^{-}\right]_{\mathrm{i}}$, change in GABA equilibrium potential $\left(\mathrm{E}_{\mathrm{GABA}}\right)$, and weakening of synaptic inhibition (Woodin et al., 2003; Fiumelli et al., 2005; Fiumelli and Woodin, 2007). Whether STDP may occur also at immature GABAergic synapses when the action of GABA is depolarizing (Cherubini et al., 1991; Ben-Ari, 2002 ) is still unclear. The depolarizing action of GABA may facilitate synaptic plasticity processes via a rise of $\left[\mathrm{Ca}^{2+}\right]_{i}$ through voltage-dependent calcium channels and NMDA receptors (Cherubini et al., 1991; Ben-Ari et al., 2007). However, these effects may be overwhelmed by the concomitant $\mathrm{GABA}_{\mathrm{A}}$ mediated shunting inhibition (Staley and Mody, 1992; Lamsa et al., 2000; Mohajerani and Cherubini, 2005; Banke and McBain, 2006).

We examined this issue at mossy fiber (MF)-CA3 synapses, which in the immediate postnatal period release mainly GABA (Safiulina et al., 2006). Pairing single postsynaptic spikes with unitary MF $\mathrm{GABA}_{\mathrm{A}}$-mediated postsynaptic potentials (GPSPs) consistently upregulated or downregulated synaptic strength ac- 
cording to the temporal order of stimulation. Positive pairing induced persistent changes in GPSPs slope, which often reached the threshold for action potential generation. STD-LTP required a rise of calcium in the postsynaptic cell via voltage-dependent calcium channel and the activation of brain-derived neurotrophic factor (BDNF) and cAMP-dependent protein kinase A. STD-LTP was prevented when GPSPs shifted from the depolarizing to the hyperpolarizing direction with bumetanide, a selective inhibitor of neuronal $\mathrm{Cl}^{-}$uptake mediated by the $\mathrm{Na}^{+}-\mathrm{K}^{+}$. $2 \mathrm{Cl}^{-}$cotransporter isoform $1 \mathrm{NKCC} 1$ (Sipilä et al., 2006).

These results indicate that in the immediate postnatal period, at mossy fiber synapses, the precise temporal correlation between GPSPs and postsynaptic spiking powerfully control synaptic strengthening or weakening thus contributing to the functional refinement of developing neuronal circuits.

\section{Materials and Methods}

Slice preparation. Experiments were performed on hippocampal slices from P2-P5 Wistar rats as described previously (Gasparini et al., 2000). All experiments were performed in accordance with the European Community Council Directive of 24 November 1986 (86/609EEC) and were approved by local authority veterinary service. Briefly, animals were decapitated after being anesthetized with an intraperitoneal injection of urethane $(2 \mathrm{~g} / \mathrm{kg})$. The brain was quickly removed from the skull and placed in ice-cold ACSF containing the following (in $\mathrm{mm}$ ): 130 $\mathrm{NaCl}, 3.5 \mathrm{KCl}, 1.2 \mathrm{NaH}_{2} \mathrm{PO}_{4}, 27 \mathrm{NaHCO}_{3}, 1.3$ $\mathrm{MgCl}_{2}, 2 \mathrm{CaCl}_{2}, 25$ glucose, saturated with $95 \%$ $\mathrm{O}_{2}$ and $5 \% \mathrm{CO}_{2}$ (pH 7.3-7.4). Transverse hippocampal slices ( $400 \mu \mathrm{m}$ thick) were cut with a vibratome and stored at room temperature $\left(20-24^{\circ} \mathrm{C}\right)$ in a holding bath containing the same solution as above. After a recovery period of at least $1 \mathrm{~h}$, an individual slice was transferred to the recording chamber where it was continuously superfused with oxygenated ACSF at a rate of $2-3 \mathrm{ml} / \mathrm{min}$ at $33-35^{\circ} \mathrm{C}$.

Electrophysiological recordings. Electrophysiological experiments were performed from CA3 pyramidal cells using the whole-cell configuration of the patch-clamp technique in current or voltage-clamp mode. Neurons were visualized using an upright microscope (Olympus BX51WI) equipped with differential interference contrast (DIC) optics and infrared video camera. Patch electrodes were pulled from borosilicate glass capillaries (Hingelberg). They had a resistance of 4-6 M $\Omega$ when filled with an intracellular solution containing the following (in mM): $140 \mathrm{KCl}, 1 \mathrm{MgCl}_{2}, 10 \mathrm{HEPES}, 4 \mathrm{MgATP}, 0.5 \mathrm{EGTA}$, $\mathrm{pH}$ 7.3. In some experiments, recordings were performed with patch pipettes containing the calcium chelator 1,2-bis (2-aminophenoxy) ethane- $N, N, N^{\prime}, N^{\prime}$-tetraacetic acid (BAPTA $20 \mathrm{~mm}$, Sigma). In these cases, to maintain the same osmolarity ( $290 \mathrm{mOsm})$, the intrapipette concentration of $\mathrm{KCl}$ was reduced to $120 \mathrm{~mm}$. Recordings were made with a patch-clamp amplifier (Axopatch 200A; Axon Instruments). Series resistance was assessed repetitively every 5 min and in current-clamp recordings compensated at $75 \%$ throughout the ex-

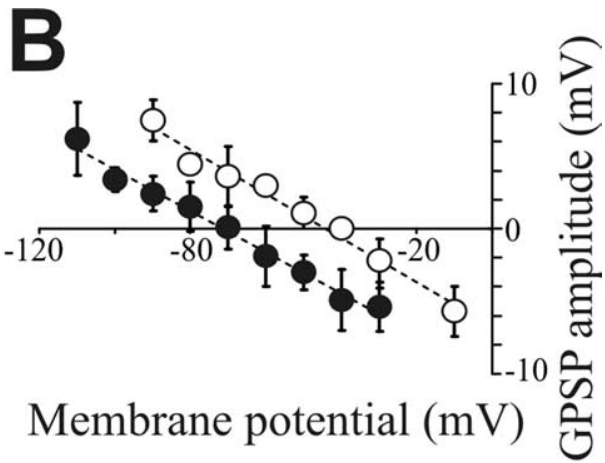

\section{L-AP4 +PTX}

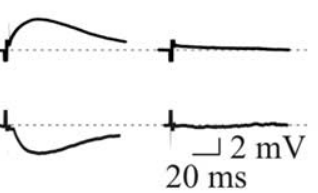

D E
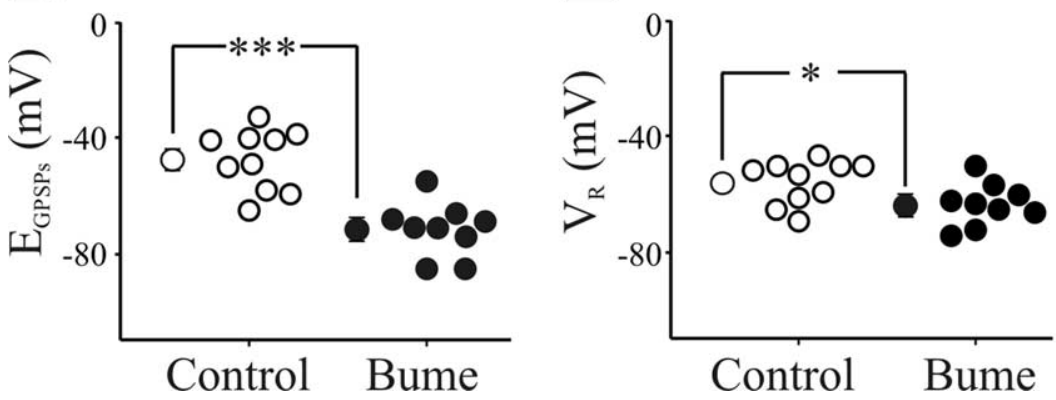

Figure 1. GABA released from MF terminals depolarizes principal cells. $A$, Synaptic responses (successes plus failures) evoked in the presence of bumetanide $(\boldsymbol{O}, 10 \mu \mathrm{m})$. B , Plot of GPSP amplitudes as a function of membrane potentials in control $(\bigcirc, n=$ $10)$ and in the presence of bumetanide $(-n=9)$. Note that in bumetanide, $\mathrm{E}_{\mathrm{GPSP}}$ shifted toward more negative values $(-71.5$ picrotoxin $(100 \mu \mathrm{M})$. In bumetanide, GPSPs were recorded at $-30 \mathrm{mV}$ to increase the driving force for $\mathrm{Cl}^{-} . \boldsymbol{D}, \boldsymbol{E}$, Each symbol values are shown on the left of each group. ${ }^{*} p<0.05 ;{ }^{* *} p<0.01 ;{ }^{* * *} p<0.001$.

periment. Cells exhibiting $>15-20 \%$ changes in series resistance were excluded from the analysis.

$\mathrm{GABA}_{\mathrm{A}}$-mediated synaptic potentials or currents (GPSPs or GPSCs) were evoked at $0.05 \mathrm{~Hz}$ from a holding potential of $-70 \mathrm{mV}$ in the presence of DNQX (20 $\mu \mathrm{M})$ and D-AP5 $(50 \mu \mathrm{M})$ to block AMPA- and NMDAmediated synaptic responses, respectively. We used minimal stimulation of the granule cells in the dentate gyrus to activate only one or few presynaptic fibers. According to the technique described by Jonas et al. (1993) and Allen and Stevens (1994), the stimulation intensity was decreased until only a single axon was activated. This was achieved when the mean amplitude of the postsynaptic currents and failure probability remained constant over a range of stimulus intensities near threshold for detecting a response (Safiulina et al., 2006). An abrupt increase in the mean peak amplitude of synaptic currents was observed when the stimulus intensity was further increased. This all or none behavior let us to assume that only a single fiber was stimulated. In addition, the latency and the shape of individual synaptic responses remained constant for repeated stimuli. The monosynaptic nature of synaptic currents was supported by the unimodal and narrow latencies and rise time distributions 
A

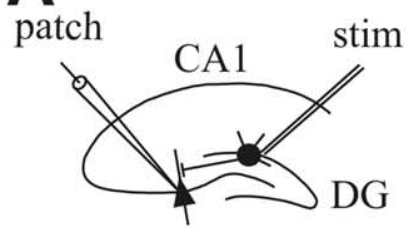

C

\section{Control After pairing}
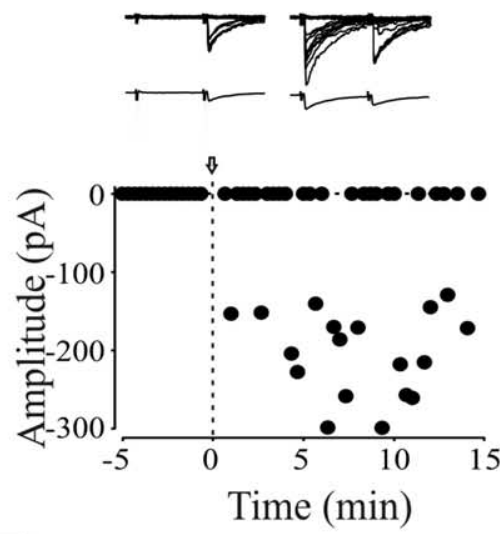

E

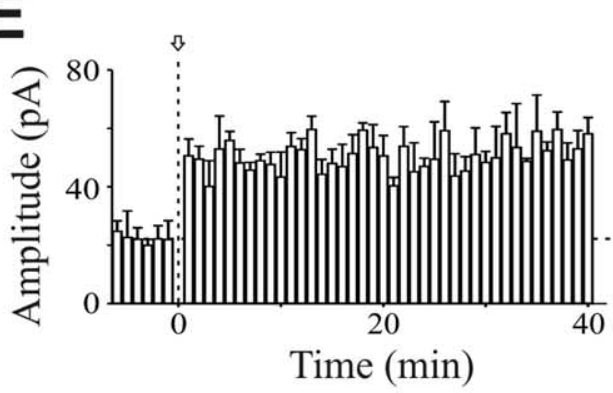

G
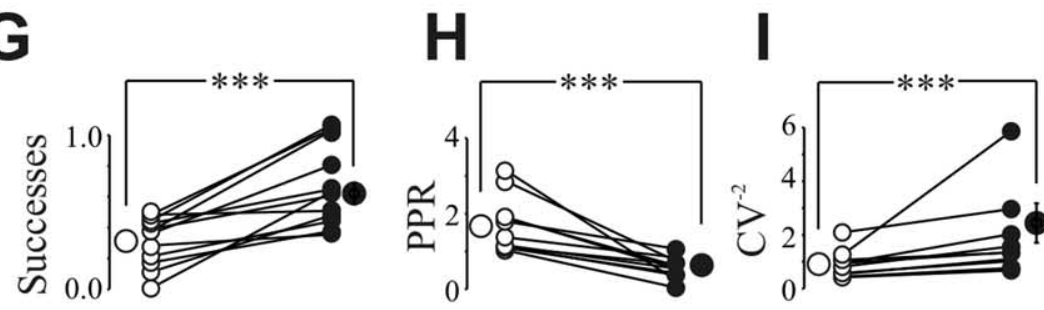

\section{Control After pairing Control After pairing Control After pairing}

Figure 2. Spike-timing dependent LTP induced by pairing MF GPSPs with postsynaptic spiking. $A$, Schematic representation of the experimental design. $\boldsymbol{B}$, Spike-timing protocol. GPSP preceded the postsynaptic spike by $15 \mathrm{~ms}(\Delta \mathrm{t}) . \boldsymbol{C}, \boldsymbol{D}$, Peak amplitude of MF GPSCs in presynaptically silent $(\boldsymbol{C})$ and low probability neurons $(\boldsymbol{D})$ evoked before and after pairing (arrows at time 0 ) as a function of time. Insets above the graphs represent individual (top traces) and averaged GPSCS (bottom traces) evoked before and after pairing. $\boldsymbol{E}$, Summary plot of mean GPSCs amplitude recorded before and after pairing versus time ( $n=12)$. $\boldsymbol{F}-\boldsymbol{I}$, Amplitude $(\boldsymbol{F})$, successes $(\boldsymbol{G})$, paired-pulse ratio $(\boldsymbol{H})$, and inverse squared of $C V(\boldsymbol{I})$ measured in individual cells before $(O)$ and $40 \mathrm{~min}$ after pairing (O). Bigger symbols represent averaged values. ${ }^{* * *} p<0.001$.

which remained constant when the extracellular $\mathrm{Ca}^{2+} / \mathrm{Mg}^{2+}$ concentration ratio was reduced from 2:1.3 to 1:3 (Safiulina et al. 2006).

When the probability of synaptic failures in response to a first stimulus was near 1 (failures were estimated by visual discrimination), we applied a second pulse at $50 \mathrm{~ms}$ interval. If a response to a second stimulus appeared in 15-30 consecutive trials (silent to the first stimulus), we considered this synapse presynaptically silent.

MF inputs were identified on the basis of their sensitivity to group III mGluR agonist 2-amino-4-phosphonobutyric acid (L-AP4 $10 \mu \mathrm{M}$ ) (Gutiérrez et al., 2003; Kasyanov et al., 2004; Safiulina et al., 2006), their strong paired pulse facilitation and short term frequency-dependent facilitation (Safiulina et al., 2006). They were blocked by bicuculline or picrotoxin, confirming their GABAergic nature. In contrast to MF inputs, GABAergic inputs from interneurons were insensitive to L-AP4 (Walker et al., 2001; Safiulina et al., 2006).

Experiments were also performed using the gramicidin-perforated patch (Kyrozis and Reichling, 1995) to preserve the anionic conditions of the recorded cells. In this case, the pipette solution contained the same intracellular solution plus $80 \mu \mathrm{g} / \mathrm{ml}$ gramicidin D (Sigma). A $20 \mathrm{mg} / \mathrm{ml}$ stock of gramicidin in dimethylsulphoxide (DMSO) was prepared freshly $(<2 \mathrm{~h}$ before recording) and sonicated. This was diluted with gramicidin-free solution, sonicated again for 20-30 s, and centrifuged. Patch pipettes were back filled with a gramicidin containing solution and then the tip of the pipette was dipped into and filled with a gramicidinfree solution by applying a negative pressure for 20-30 s to facilitate cell-attached formation (seal resistance $>3 \mathrm{G} \Omega$ ). After $\sim 40 \mathrm{~min}$, series resistance decreased and stabilized around 30 $\mathrm{M} \Omega$. The perforated patch condition was constantly monitored and in the case of membrane rupture recording was discontinued. In fact, due to the high intracellular $\left[\mathrm{Cl}^{-}\right]$, the break of the membrane was associated with a clear change in membrane capacitance and a shift of $\mathrm{E}_{\text {GPSPs }}$ near $0 \mathrm{mV}$ (Tyzio et al. 2007).

Usually, synaptic currents were recorded in voltage-clamp mode for 5-10 $\mathrm{min}$. Then, changes in synaptic efficacy, induced by pairing (in current-clamp conditions) presynaptic activity with postsynaptic spiking (10 spikes evoked at $0.1 \mathrm{~Hz}$ ) at various time intervals, were recorded for additional 15-60 min. Some experiments were performed in current-clamp mode to correlate pairing-induced changes in GPSPs slope with the probability of cell firing.

Drugs used were as follows: D-(-)-2-amino5-phosphonopentaoic acid (D-AP5), 6,7dinitroquinoxaline-2,3-dione (DNQX), L-AP4, PTX, bumetanide, Rp-cAMPS (all from Tocris Bioscience); nifedipine, forskolin, BDNF (all from Sigma); K252a, protein kinase A inhibitor 6-22 amide (PKI 6-22), protein kinase A inhibitor 14-22 amide, cell-permeable (PKI 1422) (all from Calbiochem). All drugs were dissolved in either distilled water or ethanol, as required, except DNQX, forskolin, and bumetanide, which were dissolved in DMSO. The final concentration of DMSO in the bathing solution was $0.1 \%$. At this concentration, DMSO alone did not modify the shape or the kinetics of synaptic currents. Drugs were applied in the bath via a three-way tap system, by changing the superfusion solution to one differing only in its content of drug(s). The ratio of flow rate to bath volume ensured complete exchange within 1-2 $\min$.

Data acquisition and analysis. Data were acquired and digitized with an A/D converter (Digidata 1200, Molecular Devices) and stored on a computer hard disk. Acquisition and analysis of evoked responses were performed with Clampfit 9 (Molecular Devices). Data were sampled at 20 $\mathrm{kHz}$ and filtered with a cutoff frequency of $1 \mathrm{kHz}$. Mean GPSCs amplitude was obtained by averaging successes and failures. The paired pulse 
ratio (PPR) was calculated as the mean amplitude of the synaptic response evoked by the second stimulus over that evoked by the first one. The coefficient of variation was calculated as the ratio between the SD of synaptic currents amplitude and the mean. Unless otherwise stated, data are presented as mean \pm SEM. Quantitative comparisons were based on students paired or unpaired $t$ test, as required and $p$ values $<0.05$ were considered as significant.

\section{Results}

MF inputs to principal cells were identified on the basis of their strong paired pulse facilitation, their sensitivity to group III mGluR agonist L-AP4 and their short term frequency-dependent facilitation (Kasyanov et al., 2004; Safiulina et al., 2006). MF inputs were mainly GABAergic since they were readily and reversibly blocked by bicuculline methiodide $(20 \mu \mathrm{M})$ or picrotoxin $(100 \mu \mathrm{M})$ (Walker et al., 2001; Safiulina et al., 2006). In the present experiments, GPSPs or GPSCs elicited by minimal stimulation of granule cells in the dentate gyrus were routinely recorded at $-60 \mathrm{mV}$ from CA3 pyramidal cells (at P2-P5) in the presence of DNQX (20 $\mu \mathrm{M})$ and D-AP5 $(50 \mu \mathrm{M})$ to block AMPA and NMDA receptors, respectively. These synapses were characterized by the low probability of GABA release. In several cases $(n=$ 22 ), stimulation of granule cells in the dentate gyrus failed to produce any synaptic response over 15-30 consecutive trials. However, occasional responses to a second stimulus could occur, suggesting that these synapses were presynaptically silent (Gasparini et al., 2000; Kasyanov et al., 2004) (see Fig. 2C).

\section{GABA released from $\mathrm{MF}$ terminals depolarizes principal cells}

A first set of experiments, using gramicidin-perforated patch to preserve the intracellular chloride concentration (Kyrozis and Reichling, 1995) was aimed at evaluating whether GABA released from MF terminals exerts on principal cells a depolarizing or a hyperpolarizing action. The representative example of Figure $1 A$ (Control) shows averaged responses (successes plus failures) evoked by granule cell stimulation at three different holding potentials. The reversal of GPSPs $\left(\mathrm{E}_{\mathrm{GPSP}}\right)$ was $-50 \mathrm{mV}$. Since the resting membrane potential $\left(V_{R}\right)$ of this cell was -60 $\mathrm{mV}$, the driving force for $\mathrm{GABA}$, defined as $\mathrm{E}_{\mathrm{GPSP}}-\mathrm{V}_{\mathrm{R}}$, was 10 $\mathrm{mV}$. This indicates that GABA was depolarizing (Sipilä et al., 2006; Tyzio et al., 2007). Overall, in 10 cells, $\mathrm{E}_{\mathrm{GPSP}}$ was $-47.6 \pm$ $3.3 \mathrm{mV}$ (Fig. $1 B, D$, open circles) while $\mathrm{V}_{\mathrm{R}}$ was $-56 \pm 2.2 \mathrm{mV}$ (Fig. $1 E$, open circles). $\mathrm{E}_{\mathrm{GPSP}}$ value was very close to the threshold for action potential generation $(-49.3 \pm 2.4 \mathrm{mV} ; n=21)$.

In accord with their MF origin (Gutiérrez et al., 2003, 2005; Kasyanov et al., 2004; Safiulina et al., 2006), bath application of L-AP4 $(10 \mu \mathrm{M})$ significantly reduced the amplitude of GPSPs $(34.7 \pm 8.2 \%$ of control; $n=8 ; p<0.01)$, which were completely blocked by picrotoxin $(100 \mu \mathrm{M})$ (Fig. $1 C$ ). The reduction of GP${ }^{* *} p<0.01$
B

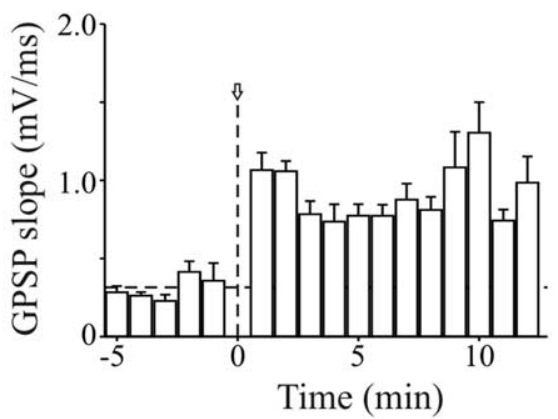

D

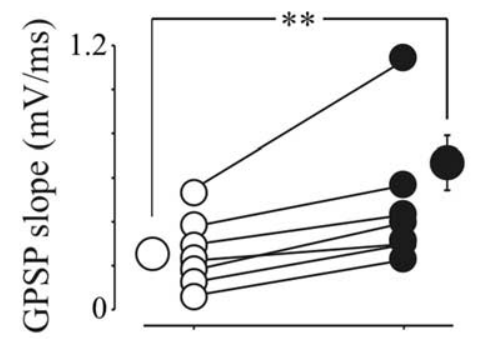

$\downarrow 10 \mathrm{mV}$

Control After pairing
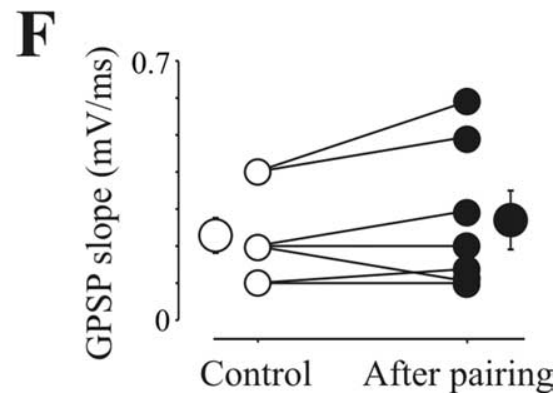

Figure 3. Pairing-induced increase in GPSPs slope was associated with enhanced firing probability. $\boldsymbol{A}$, Representative traces from one neuron showing the rising phases of GPSPs (evoked at $0.1 \mathrm{~Hz}$ ) during pairing. Note the progressive increase of GPSPs (arrows at time 0$)$ is plotted as a function of time $(n=7)$. C, Superimposed traces from a single neuron before and after pairing. . presence bumetanide before and after pairing. $\boldsymbol{F}$, Each symbol represents the mean value of GPSPS slope obtained from individual cells before $(\bigcirc)$ and $15 \mathrm{~min}$ after pairing $(\Theta)$ in the presence of bumetanide. Bigger symbols represent averaged values $(n=7)$.

SCs amplitude induced by L-AP4 was very similar to that found in a previous study for MF-evoked synaptic currents $(66 \pm 8 \%$; Safiulina et al., 2006).

To see whether accumulation of chloride inside the cell via the cation-chloride cotransporter NKCC1 was responsible for the depolarizing action of GABA, slices were incubated for 30-50 min with bumetanide $(10 \mu \mathrm{M})$, a selective inhibitor of NKCC1 (Dzhala et al., 2005; Sipilä et al., 2006). In all cells tested $(n=9)$, bumetanide caused a slight membrane hyperpolarization (on average, $\mathrm{V}_{\mathrm{R}}$ was $-63.6 \pm 2.3 \mathrm{mV} ; p<0.05$ vs controls) (Fig. $1 E$, closed circles) and a shift of $\mathrm{E}_{\mathrm{GPSP}}$ toward more negative values $(-71.5 \pm 3.09 \mathrm{mV} ; p<0.001$ respect to controls) (Fig. $1 A, B, D$, closed circles), indicating that GABA was hyperpolarizing. Also in this case, bath application of L-AP4 induced a significant reduction in amplitude of GPSPs $(34.9 \pm 8.6 \%$ of control) thus confirming their MF origin $(n=5 ; p<0.01)$ (Fig. $1 C)$. 

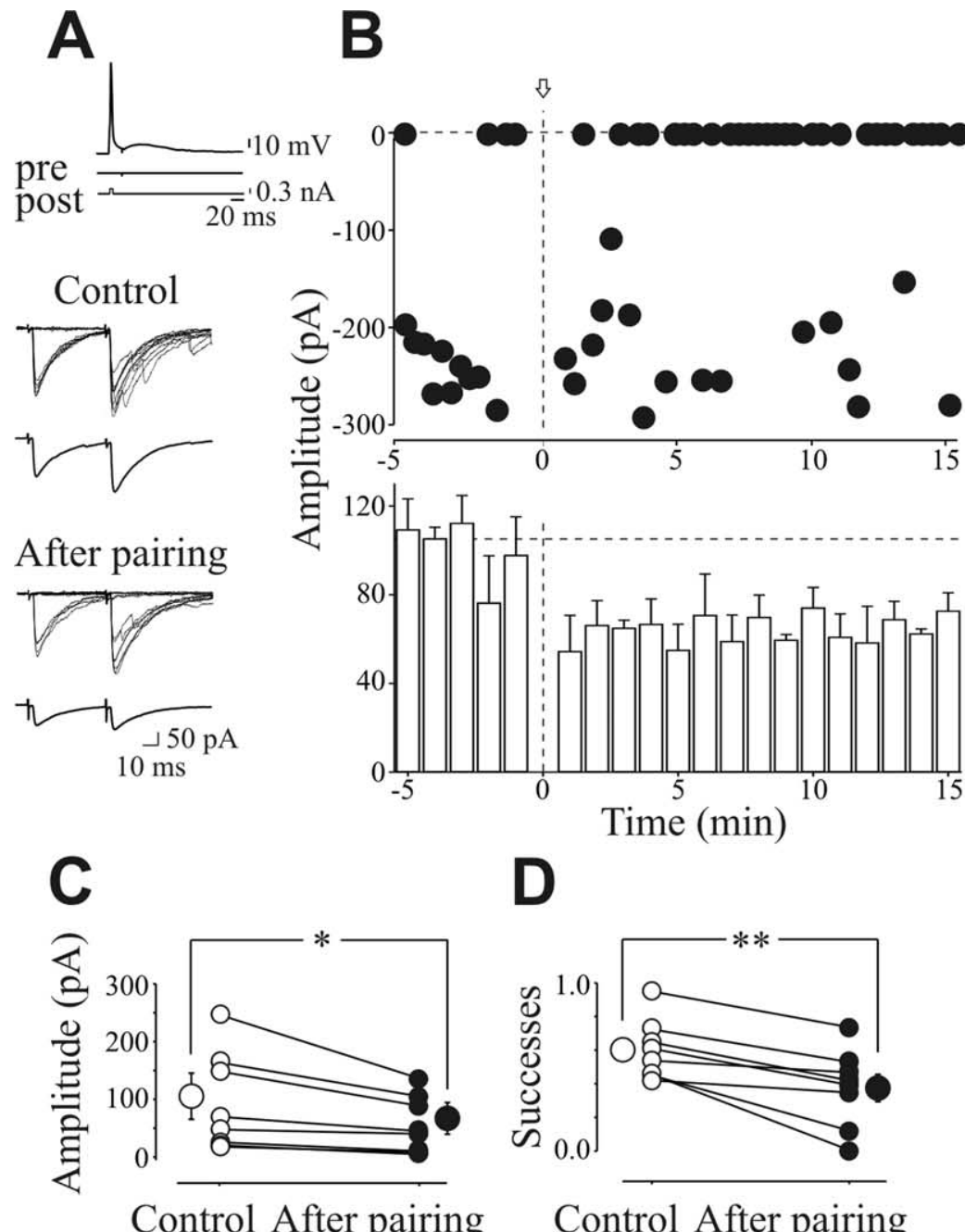

D
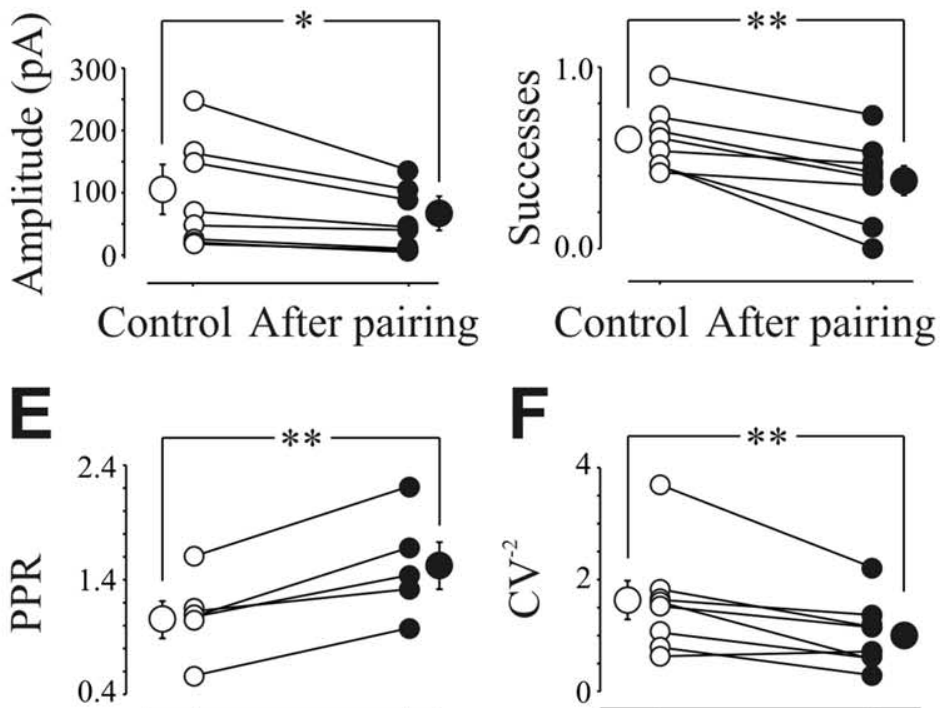

Control After pairing

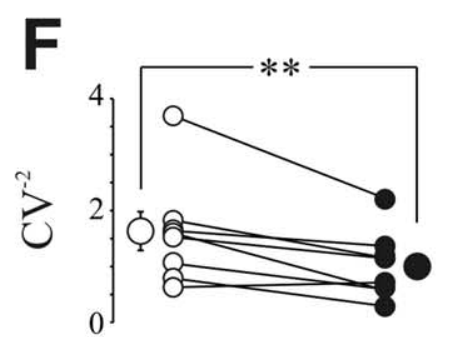

Control After pairing

Figure 4. Spike-timing dependent LTD induced by pairing MF GPSPS with postsynaptic spiking. $\boldsymbol{A}$, The inset represents the spike-timing protocol. The postsynaptic spike (post) preceded the GPSP (pre) by $15 \mathrm{~ms}$. Below, Individual (top) and averaged (bottom) traces of GPSCs evoked before (Control) and after pairing. $\boldsymbol{B}$, In the top graph, the peak amplitudes of GPSCs (shown in A) obtained before and after pairing (arrows at time 0 ) are plotted against time. In the bottom graph, summary plot of GPSCS amplitude versus time $(n=8)$. $\boldsymbol{C}-\boldsymbol{F}, \operatorname{Amplitude}(\boldsymbol{C})$, successes $(\boldsymbol{D})$, paired-pulse ratio $(\boldsymbol{E})$ and inverse squared of $\mathrm{CV}(\boldsymbol{F})$ measured in individual cells before $(\bigcirc)$ and after pairing $(O)$. Bigger circles represent average values. $(n=8$ for each group except for PPR in which $n=5)$. ${ }^{*} p<0.05{ }^{* *} p<0.01$.

These data demonstrate that at MF-CA3 synapses, due to the accumulation of $\mathrm{Cl}^{-}$inside the cell by NKCC1, GABA exerts a depolarizing action.

\section{Bidirectional modifications of synaptic strength associated with STDP}

In the next series of experiments, we used a pairing procedure to verify whether STDP could modify synaptic efficacy. STDP was in-

duced in current-clamp mode by pairing 10 postsynaptic spikes (at $0.1 \mathrm{~Hz}$ ) with afferent stimulation, varying the relative timing of presynaptic and postsynaptic activity (Fig. $2 A, B)$. Postsynaptic firing without presynaptic activation caused no changes in synaptic efficacy (the amplitude of GPSCs was $-28.6 \pm 3.2 \mathrm{pA}$ and $-29.3 \pm 2.8 \mathrm{pA}$, before and after postsynaptic firing, respectively, $n=6)$. In addition, no changes in synaptic efficacy were detected changing stimulation frequency from 0.05 to $0.1 \mathrm{~Hz}$ in the absence of postsynaptic spikes ( $n=4$; data not shown). Coincident presynaptic and postsynaptic activity (0 ms delay) did not modify synaptic strength. However, a delay of $15 \mathrm{~ms}$ (pre before post) (Fig. 2B) caused a strong potentiation of GPSCs. Examples of presynaptically silent or low probability synapses are shown in Figure 2, $C$ and $D$, respectively. In both cases, correlated activity (arrows) induced an increase in GPSCs amplitude and successes rate which persisted without decrement for periods of time variable from 40 to $60 \mathrm{~min}$ indicating that changes in synaptic efficacy were persistent as in LTP. The time course of pairinginduced modifications of synaptic strength observed in 12 cells (including one presynaptically silent) recorded for at least $40 \mathrm{~min}$ after pairing is illustrated in Figure 2E. On average, the peak amplitude of GPSCs (successes plus failures) was $21.5 \pm 4.1 \mathrm{pA}$ and $51.9 \pm 13.1 \mathrm{pA}$, before and $15 \mathrm{~min}$ after pairing $(p<0.001)$ (Fig. $2 F)$, respectively, while the success rate changed from $0.31 \pm 0.04$ to $0.62 \pm 0.07(p<0.001)$ (Fig. $2 G)$. These effects were associated with a significant reduction of the PPR (from $1.66 \pm 0.22$ to $0.64 \pm 0.09 ; p<0.001$ ) (Fig. $2 H$ ) and a significant increase in the inverse squared value of the coefficient of variation $\left(\mathrm{CV}^{-2}\right)$ of responses amplitude (from $0.91 \pm 0.14$ to $2.43 \pm 0.73 ; p<0.001 ; n=19$, Fig. 2 I). The PPR was measured only in nonsilent cells. After pairing the potency of synaptic responses (mean amplitude of successes without failures) increased significantly (from $53.9 \pm 12.1 \mathrm{pA}$ to $90.1 \pm 13.9 \mathrm{pA} ; p<0.01)$.

Positive pairing (with $15 \mathrm{~ms}$ delay) was also performed in current-clamp conditions (using gramicidin-perforated patch) to measure changes in GPSPs slope and in the probability of firing. As shown in Figure $3, B$ and $D$, pairing always $(7 / 7)$ induced a stable potentiation of GPSP slope (from $0.25 \pm 0.05$ to $0.67 \pm 0.12 ; n=7 ; p<0.01)$ which sometimes initiated during the pairing protocol (Fig. $3 A$; note that in this case changes in GPSPs slope triggered action potentials). Due to the larger size of synaptic events, after pairing it was easier to reach the threshold for action potential generation (after pairing, the probability of cell firing persistently increased from 0.04 to 0.5 ) (Fig. 3C).

STD-LTP did not depend on changes in the equilibrium po- 


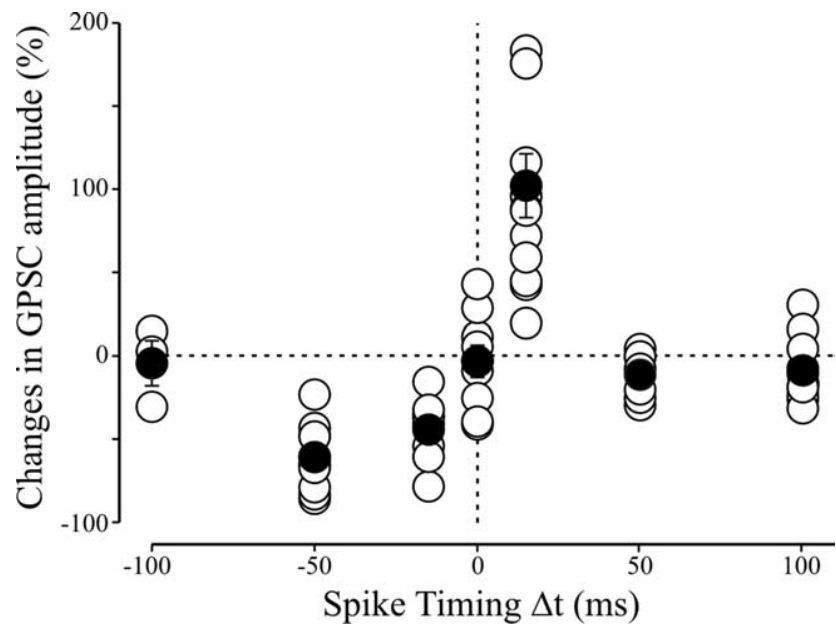

Figure 5. Temporal window for spike-timing dependent enhancement and reduction in the efficacy of MF GPSCs. Plot of GPSC amplitude (as percentage of controls) from individual cells (○) as a function of $\Delta t$. Closed symbols represent the averaged values for each $\Delta t$. No changes in amplitude were detected when the postsynaptic action potential was coincident with presynaptic GPSPs ( $\Delta t=0 \mathrm{~ms}$ ). Note that the magnitude of synaptic potentiation reached the maximum at $\Delta t=15 \mathrm{~ms}$ which corresponds to the peak of GPSP.

tential for GABA since similar $\mathrm{E}_{\mathrm{GPSP}}$ values were found before and after pairing $(-48.3 \pm 2.5 \mathrm{mV}$ and $-43.8 \pm 4.1 \mathrm{mV}$, respectively; $n=7$ ) (supplemental Fig. S1, available at www.jneurosci. org as supplemental material). These data indicate that correlating presynaptic and postsynaptic activity strongly enhances the amplitude of GABA-mediated synaptic events leading to excitation of principal cells. In cells treated with bumetanide $(10 \mu \mathrm{M})$, the pairing protocol did not modify the slope of hyperpolarizing GPSPs (Fig. $3 E, F)(n=7)$.

STD-LTP probably did not depend on general changes in intrinsic membrane properties of principal cells or changes in presynaptic cell excitability, because the pairing procedure did modify neither the threshold for action potential generation $(-49.3 \pm$ $1.5 \mathrm{mV}$ and $-47.9 \pm 2.1 \mathrm{mV}$ before and after pairing, respectively; $n=7$ ) nor the firing frequency in response to depolarizing current pulses (supplemental Fig. S2, available at www.jneurosci. org as supplemental material).

Negative pairing (post before pre) (Fig. 4A) with a 15 ms delay was assessed in synapses with relatively high probability of release. This procedure induced a consistent depression of MFmediated GPSCs. After pairing, the mean peak amplitude of GPSCs (successes plus failures) shifted from $105.3 \pm 40.0 \mathrm{pA}$ to $66.9 \pm 27.4 \mathrm{pA}(n=8 ; p<0.05)$ (Fig. $4 A, B)$. This was mainly caused by a decrease in the number of successes (from $0.61 \pm 0.06$ to $0.38 \pm 0.08$, before and after pairing, respectively; $n=8 ; p<$ 0.01 ) (Fig. $4 B, D$ ). The potency of the responses (mean amplitude of successes without failures) was almost unchanged (174 \pm 49.7 $\mathrm{pA}$ and $150.5 \pm 36.9 \mathrm{pA}$ before and after pairing, respectively; $p>$ 0.1 ; data not shown). As expected for a reduction in the probability of GABA release, the increased number of failures was associated with a significant increase in PPR (from $1.04 \pm 0.16$ to $1.52 \pm 0.20 ; n=5 ; p<0.01$ ) (Fig. $4 E$ ) and a significant decrease of $\mathrm{CV}^{-2}$ (from $1.63 \pm 0.35$ to $1.0 \pm 0.2 ; n=8 ; p<0.01$ ) (Fig. $4 F)$.

The time window for bidirectional activity-dependent changes in synaptic efficacy is summarized in Figure 5. When the action potential was coincident with the GPSP, no changes in synaptic strength were detected. However, when the postsynaptic spike followed the GPSP onset with 15 ms delay (which corre- sponds to the peak of the synaptic event), the magnitude of synaptic potentiation reached its maximum. GPSP potentiation declined toward control level with delays of $>50 \mathrm{~ms}$. On the contrary, when the postsynaptic spike preceded the GPSP we observed a depression of the synaptic responses that regained the control level with delays of $>50 \mathrm{~ms}$. Overall, these data indicate that activity-dependent changes in synaptic efficacy strongly rely on the temporal relationship between presynaptic and postsynaptic activation being the critical window for STDP similar to that described for most glutamatergic and GABAergic synapses (Dan and Poo, 2006).

\section{Pairing-induced synaptic potentiation requires a rise of calcium in the postsynaptic cell via voltage-dependent calcium channels}

A common trigger for LTP is a postsynaptic rise in intracellular calcium concentration (Malenka and Nicoll, 1999). To test whether a rise of postsynaptic calcium during STDP is responsible for the increase in synaptic efficacy, cells were loaded with the calcium chelator BAPTA $(20 \mathrm{~mm})$. In these cases, the pairing procedure failed to cause any persistent increase of synaptic strength. Instead, a persistent depression of synaptic currents was observed (Fig. 6A,B) (Kasyanov et al. 2004). In the presence of BAPTA, the mean amplitude of GPSCs measured before and after pairing was $-36.9 \pm 5.3 \mathrm{pA}$ and $-22.1 \pm 2.6 \mathrm{pA}$, respectively $(n=6 ; p=0.01)$. These experiments suggest that at MF-CA3 synapses, pairing-induced LTP depends on calcium rise in the postsynaptic cell. This may occur via voltage-dependent calcium channels or via NMDA receptors (Leinekugel et al., 1997; Garaschuk et al., 1998; Kasyanov et al., 2004). NMDA receptors were not involved, because as already reported, all experiments were routinely performed in the presence of D-AP5 (50 $\mu \mathrm{M})$ (Fig. $6 A, B)$. However, pairing-induced synaptic potentiation was prevented by nifedipine $(10 \mu \mathrm{M})$, indicating the involvement of voltage-dependent L-type of calcium channels. The mean amplitude of GPSCs, measured before and after pairing was $-46.3 \pm$ $9.2 \mathrm{pA}$ and $-22.2 \pm 6.8 \mathrm{pA}$, respectively; $n=5 ; p>0.1$ (Fig. $6 A, B)$. These results indicate that, early in postnatal life, calcium rise through VDCC triggers STD-LTP. In the following experiments, we focused only on the signaling pathways involved in STD-LTP.

\section{Pairing-induced synaptic potentiation requires the activation of TrkB receptors by $\mathrm{BDNF}$}

The present data clearly show that the induction of STD-LTP is postsynaptic while its expression is presynaptic as suggested by the decrease in PPR and by the increase in $\mathrm{CV}^{-2}$ of MF-mediated synaptic responses. Therefore, the postsynaptic cell shall provide a transcellular retrograde signal to the presynaptic neuron. One attractive candidate is BDNF, which can be released in a calciumdependent way by depolarization of the postsynaptic cell (Goodman et al., 1996; Lessmann et al., 2003; Magby et al., 2006; Kuczewski et al., 2008b). Previous studies from the immature hippocampus have shown that BDNF is the retrograde messenger required for increasing the probability of GABA and glutamate release at GABAergic and glutamatergic synapses, respectively (Gubellini et al., 2005; Mohajerani et al., 2007). Therefore, we tested whether BDNF was able to mimic the effects of STD-LTP on MF-evoked GPSCs. As illustrated in Figure 7A, in the absence of BDNF, no changes in synaptic efficacy were detected $(n=5)$. Bath application of BDNF (40 ng/ml for $5 \mathrm{~min}$ ), however, produced a significant increase in amplitude of GPSCs (from $20.3 \pm$ $4.2 \mathrm{pA}$ to $44.7 \pm 7.5 \mathrm{pA} ; p<0.01 ; n=7$ ) which persisted for at 
A

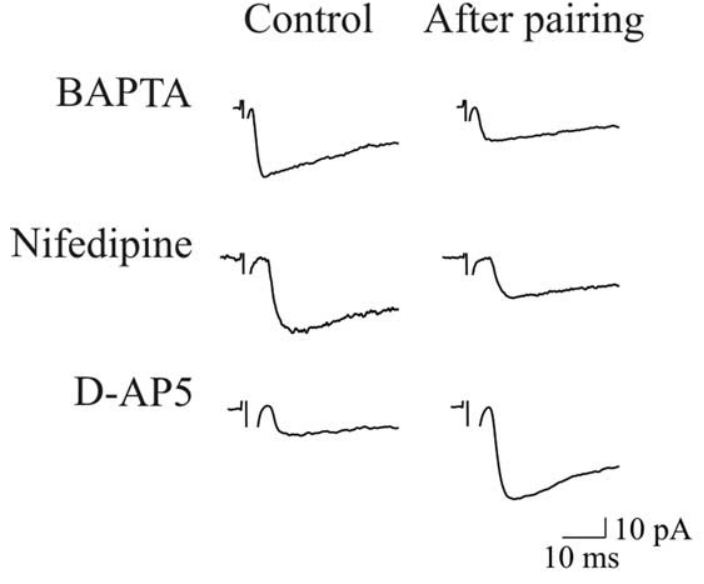

B

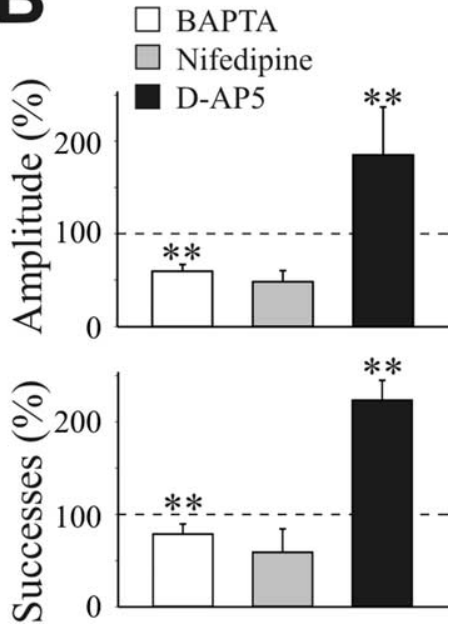

Figure 6. Pairing-induced potentiation requires a postsynaptic rise of intracellular calcium via voltage-dependent calcium channels. A, Averaged traces of GPSC evoked before and 15 min after pairing in neurons loaded with intracellular BAPTA (20 mm) or exposed to extracellular solutions containing nifedipine (10 $\mu \mathrm{M})$ or D-AP5 $(50 \mu \mathrm{M})$. B , Pairing-induced changes in the mean amplitude and mean number of successes expressed as percentage of controls from all cells tested (BAPTA, $n=6$ ), nifedipine $(n=5)$ and D-AP5 $(n=5) .{ }^{* *} p<0.01$.

least 10-15 min after BDNF was washed out (Fig. $7 B, C$ ). This effect was associated with a significant increase in the number of successes (from $0.24 \pm 0.05$ to $0.59 \pm 0.07 ; p<0.01$ ) (Fig. $7 D$ ) and a significant decrease in PPR (from $2.63 \pm 0.4$ to $0.52 \pm 0.22$; $p<0.01$ ) (Fig. 7E). The effects of BDNF were prevented by bath application of $\mathrm{K} 252 \mathrm{a}(150 \mathrm{nM})$, a specific inhibitor of protein tyrosine kinase coupled to TrkB receptors $(n=5)$ (supplemental Fig. S3, available at www.jneurosci.org as supplemental material) (Knüsel and Hefti, 1992), indicating that this neurotrophin was acting on TrkB receptors. The involvement of endogenous BDNF in pairing-induced synaptic potentiation was assessed using K252a. Bath application of K252a (150 nM) fully prevented STDLTP. Surprisingly, in the presence of K252a, a persistent depression of synaptic currents was observed (mean GPSCs amplitude was $45.2 \pm 6.7 \mathrm{pA}$ and $32.1 \pm 4.4 \mathrm{pA}$, before and after pairing, respectively; $n=7 ; p<0.05$ ) (Fig. $7 F-H$ ). This effect was associated with a reduced number of successes and an increase in PPR $(0.75 \pm 0.18$ and $0.99 \pm 0.21$, before and after pairing, respectively, $p<0.01$ ) (Fig. $7 I, J$ ) suggesting a presynaptic site of action. The mechanisms underlying K252a-induced synaptic depression are still unclear and further experiments need to elucidate this issue. In the absence of pairing, K252a alone did not modify the amplitude or kinetics of GPSCs (amplitude: $38.2 \pm 4.6 \mathrm{pA}$ and $37.9 \pm 5.8 \mathrm{pA}$, in control and in the presence of $\mathrm{K} 252 \mathrm{a}$, respectively; $n=5$ ).

Altogether, these data show that at immature MF-CA3 synapse endogenous BDNF is crucial for STD-LTP induction

\section{Pairing-induced synaptic potentiation requires the activation of cAMP-dependent PKA}

In the neonatal rodent hippocampus, LTP requires the activation of cAMP-dependent protein kinase A (PKA) (Yasuda et al., 2003). Therefore, in the following experiments we tested whether at MF-CA3 synapses STD-LTP requires the activation of cAMPdependent PKA. First, we tested the effects of forskolin, an activator of adenylyl cyclase. Bath application of forskolin (50 $\mu \mathrm{M}$ for 5 min) mimicked the effects of BDNF and induced a significant increase in amplitude of GPSCs (from $45.4 \pm 11.1 \mathrm{pA}$ in control to $72.6 \pm 12.9 \mathrm{pA}, 10 \mathrm{~min}$ after forskolin; $p<0.01 ; n=6$ ) (Fig.

$8 A, B)$ which persisted for at least $15 \mathrm{~min}$ after forskolin was washed out. This effect was associated with a significant increase in the number of successes (from $0.37 \pm$ 0.08 to $0.63 \pm 0.10 ; p<0.01$ ) (Fig. $8 C$ ), in the $\mathrm{CV}^{-2}$ (from $0.69 \pm 0.18$ to $2.79 \pm$ $1.04 ; p<0.05)$ (Fig. $8 E$ ) and a decrease in PPR (from $1.12 \pm 0.29$ to $0.38 \pm 0.13 ; p<$ 0.05) (Fig. 8D).

In subsequent experiments, the involvement of endogenous cAMPdependent PKA in STD-LTP was assessed using the selective cell permeant inhibitor Rp-cAMPS. As illustrated in Figure 9, in the presence of Rp-cAMPS $(20 \mu \mathrm{M})$, positive pairing failed to potentiate MFmediated synaptic currents suggesting that changes in synaptic efficacy requires the activation of both BDNF and cAMPdependent PKA (peak amplitudes were $20.1 \pm 5.4 \mathrm{pA}$ and $17.1 \pm 4.3 \mathrm{pA}$, successes rate $0.34 \pm 0.1$ and $0.31 \pm 0.1$, the PPR $1.09 \pm 0.2$ and $1.03 \pm 0.2$ and $\mathrm{CV}^{-2}$ $0.51 \pm 0.08$ and $0.6 \pm 0.06$, before and after pairing, respectively).

Since cAMP has been shown to regulate the recruitment of TrkB receptors to the plasma membrane (Meyer-Franke et al., 1998) and to gate the effects of BDNF on hippocampal neurons (Ji et al., 2005), we tested whether inhibitors of cAMP or PKA were able to prevent the potentiating effects of BDNF on GPSCs. In two separate set of experiments, bath application of RpcAMPS $(20 \mu \mathrm{M} ; n=8)$ or PKI $14-22(1 \mu \mathrm{M} ; n=6)$, a cellpermeable inhibitor of PKA, fully prevented the effects of BDNF on GPSCs (supplemental Fig. S4, available at www.jneurosci.org as supplemental material). Finally, to identify the presynaptic or postsynaptic site of PKA action, positive pairing was performed in cells loaded with the membrane impermeable form of PKI (PKI 6-22, $1 \mu \mathrm{M} ; n=7$ ). In these conditions, correlated presynaptic and postsynaptic activity failed to produce any persistent change in synaptic strength (Fig. $10 A, B$ ). In the presence of PKI $6-22$, peak amplitudes of GPSCs were $26.0 \pm 3.6 \mathrm{pA}$ and $24.9 \pm$ $7.3 \mathrm{pA}$, successes rate $0.34 \pm 0.06$ and $0.33 \pm 0.07, \mathrm{PPR} 1.47 \pm$ 0.12 and $1.33 \pm 0.28$ and $\mathrm{CV}^{-2} 0.76 \pm 0.11$ and $0.75 \pm 0.17$, before and after pairing, respectively.

This indicates that PKA activity in the postsynaptic neuron plays a crucial role in STDP.

\section{Discussion}

It is known that, in particular conditions, MF can release, in addition to glutamate, GABA (Walker et al., 2001; Gutiérrez et al., 2003, 2005), and a recent study from our laboratory has demonstrated that, early in development, the main neurotransmitter released from MF is GABA (Safiulina et al., 2006). During postnatal development, granule cells transiently express both mRNA coding for GAD 67 and GAD 67 protein (Dupuy and Houser, 1997; Frahm and Draguhn, 2001). This GABAergic phenotype has been attributed either to principal cells synthesizing GABA, which would be downregulated in adulthood (Frahm and Draguhn, 2001) or to GAD-positive interneurons which would transiently migrate to the upper and middle portions of the granule cell layer (Dupuy and Houser, 1997; Uchigashima et al., 2007). Whatever their origin, MF-mediated GPSCs exhibited all characteristics of MF responses such as strong paired pulse facilitation, 
short term frequency-dependent facilitation and sensitivity to the group III mGluR agonist L-AP4 (Salin et al., 1996; Safiulina et al., 2006). In addition, hyperpolarizing GPSPs evoked by dentate gyrus stimulation in the presence of bumetanide were also sensitive to L-AP4 further indicating their MF origin (monosynaptic responses obtained in principal cells by stimulating GABAergic interneurons were unaffected by L-AP4) (Walker et al., 2001; Doherty et al., 2004; Kasyanov et al., 2004; Gutiérrez, 2005; Safiulina et al., 2006).

GABA released from MF exerted a depolarizing action on CA3 pyramidal neurons as assessed by measuring the driving force for $\mathrm{GABA}\left(\mathrm{E}_{\mathrm{GPSP}}-\mathrm{V}_{\mathrm{R}}\right)$ which was positive to $V_{R}$. $G A B A$ not only exerted a depolarizing action but after positive pairing triggered action potential firing. This effect was not due to changes in intrinsic membrane properties of tagged cells or modifications in $\mathrm{E}_{\mathrm{GPSP}}$, since similar firing properties and $\mathrm{E}_{\mathrm{GPSP}}$ values were observed before and after pairing. Unlike the present experiments, in cultured hippocampal neurons bearing depolarizing responses to GABA, repetitive postsynaptic spiking within $\pm 5 \mathrm{~ms}$ of $\mathrm{GABA}_{\mathrm{A}}$ mediated synaptic transmission was able to downregulate the expression of the cation-chloride cotransporter NKCC1 leading to a reduction in $\left[\mathrm{Cl}^{-}\right]_{\mathrm{i}}$ and a shift of $\mathrm{E}_{\mathrm{Cl}}$ below $\mathrm{V}_{\mathrm{R}}$ (Balena and Woodin, 2008). It should be stressed, however, that while in our experiments the STDP protocol consisted in 10 pairs of single postsynaptic spikes with unitary GPSPs, cultured neurons were stimulated with 150 pairs of presynaptic and postsynaptic spikes at 5 Hz. In addition, in our case the temporal correlation between weak inputs (single MF-mediated synaptic events) and strong inputs (back propagating action potential) dictated the direction of synaptic changes toward potentiation or depression. The temporal window responsible for LTP and LTD was very similar to that reported in previous studies for glutamatergic synapses (Magee and Johnston, 1997; Markram et al., 1997; Bi and Poo, 1998; Debanne et al. 1998; Zhang et al., 1998), suggesting the similar learning rules regulate STDP at GABAergic connections.

As in other forms of developmental plasticity (Gaiarsa et al., 2002; Kasyanov et al., 2004; Mohajerani et al., 2007), calcium entering into the cell through VDCCs was responsible for positive changes in synaptic efficacy as demonstrated by the lack of STD-LTP when BAPTA was present in the recording pipette or when nifedipine was added to the extracellular solution. In accord to the calcium hypothesis, the direction of synaptic changes would be determined by distinct calcium $0.05 ;{ }^{* *} p<0.01$.
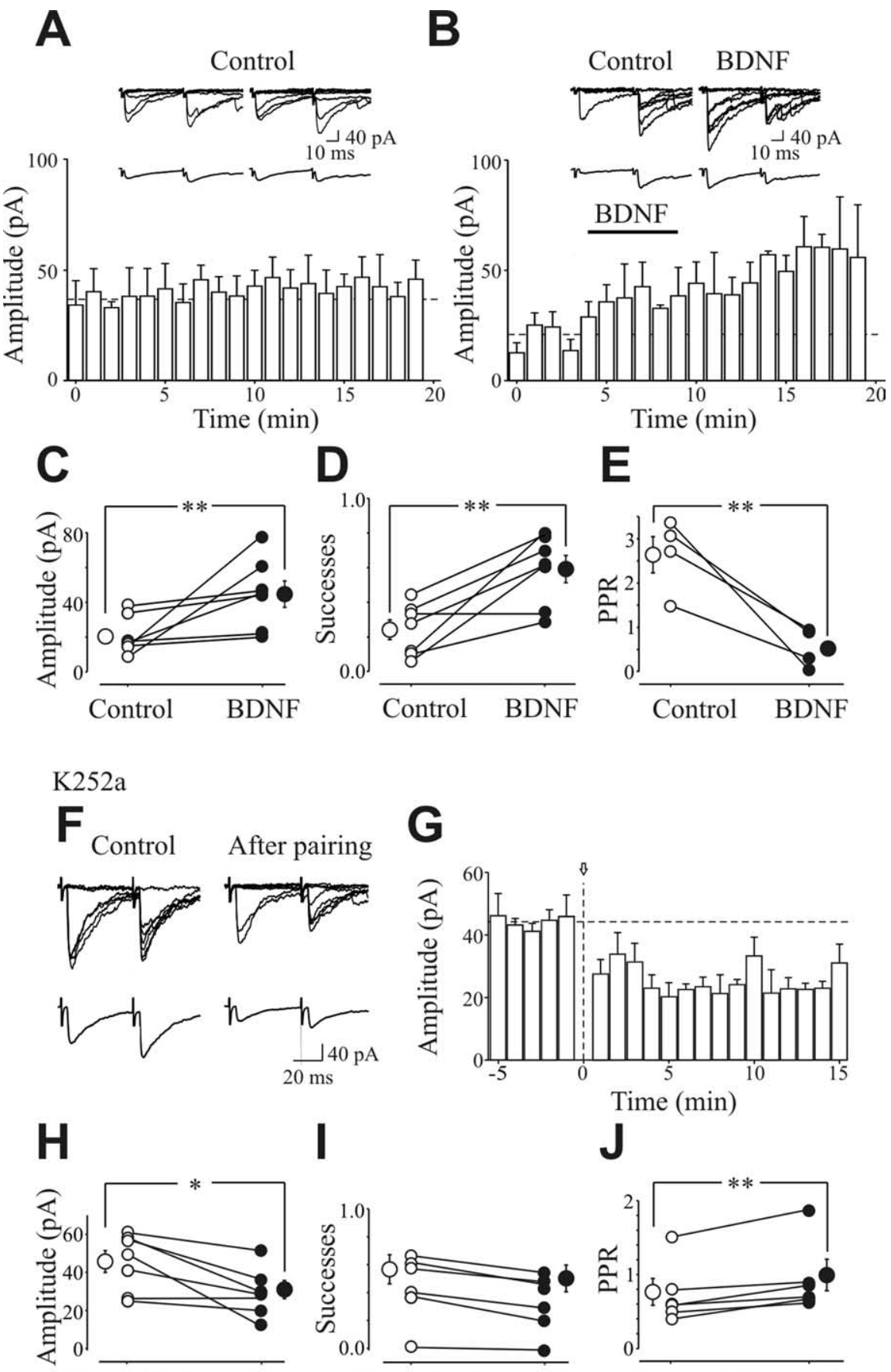

Control After pairing
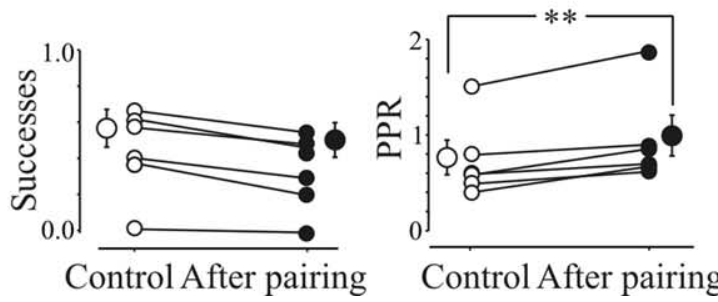

Figure 7. Pairing-induced synaptic potentiation requires the activation of TrkB receptors by BDNF. A, Summary plot showing the mean amplitude of GPSCs versus time in the absence of BDNF (Control; $n=5$ ). Insets above the graph refer to GPSCs (individual traces above and averaged traces below) recorded during the first (left) and the last (right) $5 \mathrm{~min}$. B, Summary plot showing the mean amplitude of GPSC ( $n=7)$ evoked before, during and after bath application of BDNF (bar). The horizontal dashed line represents the mean amplitude of GPSCs recorded in control before BDNF application. Insets above the graph represent superimposed individual (top) and averaged (bottom) traces of GPSCs evoked before (Control) and 15 min after the application of BDNF $(40 \mathrm{ng} / \mathrm{ml})$. $(-\boldsymbol{E}$, Amplitude $(\boldsymbol{C})$, successes $(\boldsymbol{D})$ and paired-pulse ratio $(\boldsymbol{E})$ measured in individual cells before $(O)$ and 15 min after BDNF (O). Larger symbols represent averaged values. $\boldsymbol{F}-\boldsymbol{J}$, As in Figure 2 but in the presence of K252a $(n=7)$. ${ }^{*} p<$

signals which would activate different molecular pathways (Caporale and Dan, 2008). However, in the present case, positive pairing in the presence of BAPTA not only prevented LTP but induced LTD, suggesting that synaptic depression is tightly regulated by the amount of calcium entering into the postsynaptic 

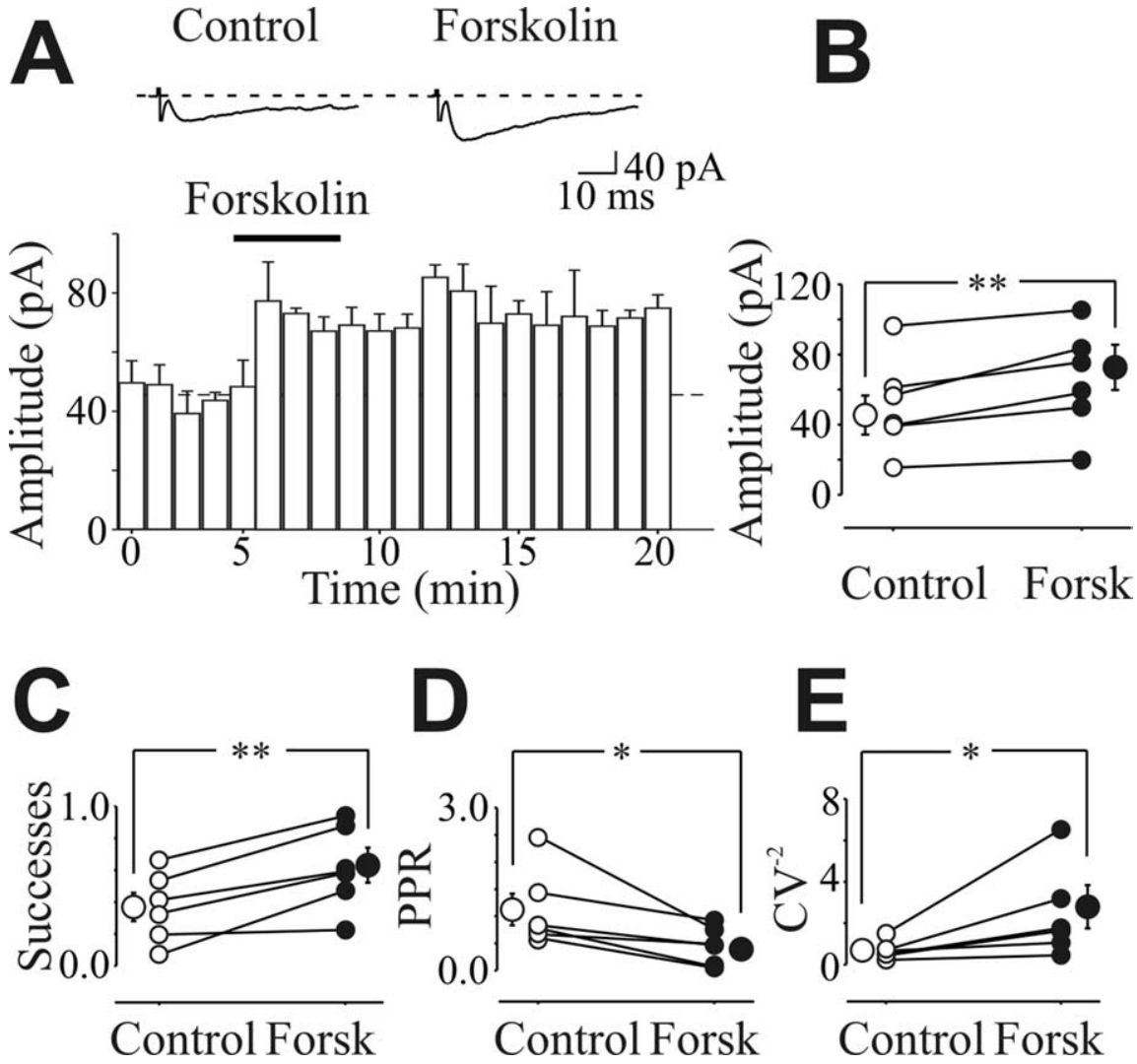

Figure 8. Forskolin mimics the effects of BDNF. $A$, Summary plot showing the mean amplitude of GPSC $(n=6)$ evoked before, during and after bath application of forskolin (50 $\mu \mathrm{M}$, bar). Insets above the graph show averaged traces (15 GPSCs from a representative neuron) evoked before and during bath application of forskolin. $\boldsymbol{B}-\boldsymbol{E}$, Amplitude $(\boldsymbol{B})$, successes $(\boldsymbol{C})$, paired-pulse ratio $(\boldsymbol{D})$ and inverse squared of $\mathrm{CV}(\boldsymbol{E})$ measured before $(\bigcirc)$ and during bath application of forskolin $(\boldsymbol{O})$. Larger symbols represent averaged values. ${ }^{*} p<0.05 ;{ }^{* *} p<0.01$.

\section{Rp-cAMPS}

\section{Control}

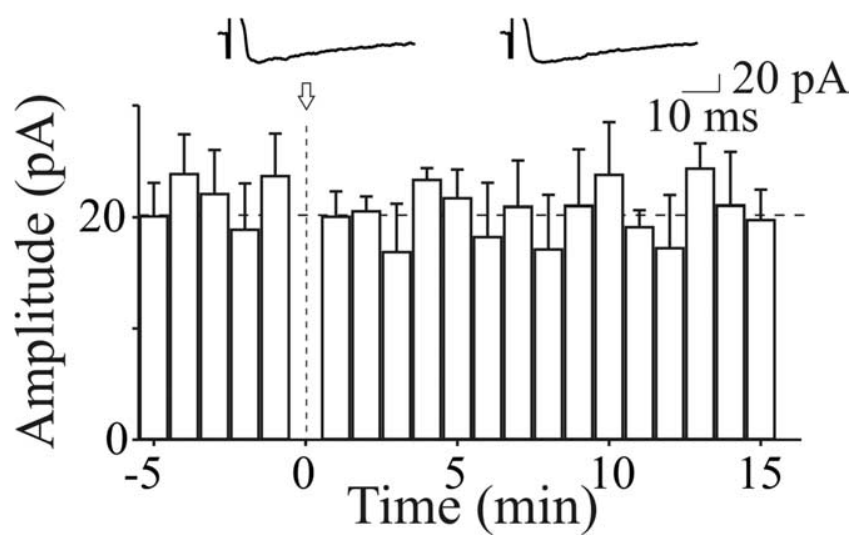

Figure 9. Pairing-induced synaptic potentiation requires the activation of cAMP-dependent PKA. Summary plot showing the mean amplitude of GPSC ( $n=5$; average of 12 traces) evoked in the presence of Rp-CAMPS before and after pairing (arrows at time 0 ) as a function of time. Insets above the graph represent individual traces of GPSCs evoked before and after pairing.

cell. While the induction of STD-LTP was clearly postsynaptic, its expression was presynaptic, as indicated by the pairing-induced decrease in failures rate, in paired-pulse facilitation, and increase in $\mathrm{CV}^{-2}$, all traditional indices of changes in presynaptic release probability (Zucker, 1989). Changes in failure rate and $\mathrm{CV}^{-2}$ could result from the insertion of new receptors on the subsynaptic membrane in silent synapses (Kullmann, 2003). Moreover, pairinginduced appearance of GPSCs in apparently "presynaptically silent" neurons is consistent with an increase in release probability (Gasparini et al., 2000). Similar to our findings, even in mature GABAergic synapses, activity-dependent modifications required a postsynaptic calcium rise through VDCCs (Woodin et al., 2003; Haas et al., 2006). However, in these cases, a presynaptic expression mechanism was excluded because no changes in paired pulse ratio were detected.

The postsynaptic induction of STDLTP and its presynaptic expression implies the existence of cross talk between the post and presynaptic neuron and the involvement of a transcellular retrograde signal. One attractive candidate is BDNF, which plays a crucial role in synaptic plasticity (Poo, 2001), in $\mathrm{GABA}_{\mathrm{A}}$-mediated LTP (Gubellini et al., 2005), and is known to be a potent regulator of spontaneous correlated network activity at early developmental stages (Aguado et al., 2003; Carmona et al., 2006). Although several lines of evidence indicate that BDNF can be released in a calcium-dependent way by depolarization of the postsynaptic cell (Goodman et al., 1996; Lessmann et al., 2003; Magby et al., 2006; Kuczewski et al., 2008a,b), the present data do not allow identifying the presynaptic or postsynaptic site of BDNF release. However, the recent observation of a calcium-dependent dendritic release of BDNF following spontaneous or evoked back propagating action potentials in hippocampal neurons in culture, strongly support a postsynaptic locus (Kuczewski et al., 2008b). Interestingly, as in the present experiments, only a few spikes (eight at $4 \mathrm{~Hz}$ ) were sufficient to trigger BDNF secretion (Kuczewski et al., 2008b). Once released, BDNF would interact with high affinity TrkB receptors localized on both presynaptic and postsynaptic membranes. Activation of presynaptic TrkB receptors would lead to an increase in transmitter release ( $\mathrm{Li}$ et al., 1998) (for review, see Poo, 2001; Du and Poo, 2004). In the present experiments, the involvement of BDNF in STD-LTP was demonstrated by the capability of this neurotrophin to mimic the effects of pairing on amplitude, successes rate and PPR of GPSCs and by the observation that SDT-LTP was prevented by K252a, a tyrosine kinase inhibitor. It is worth noting that in the presence of K252a the pairing procedure led to synaptic depression. Although this effect was clearly presynaptic, as indicated by the increase in PPR, the underlying mechanism is unclear. A tonic activation of TrkB receptor by endogenous BDNF can be excluded since K252a alone did not affect synaptic transmission.

At excitatory synapses, the long-term effects of BDNF on activity-dependent synaptic plasticity, has been found to be regulated by cAMP-dependent PKA. This molecule would exert a permissive role by enhancing the sensitivity to BDNF (Boulanger and Poo, 1999), by increasing TrkB phosphorylation (Ji et al., 
2005) and by recruiting TrkB receptors to dendritic spines (Meyer-Franke et al., 1998) (for review, see Nagappan and Lu, 2005). Consistent with these studies, STDLTP of MF-GPSCs was blocked by RpcAMPS and PKI 14-22, indicating that endogenous BDNF required the activity of cAMP-dependent PKA. In the present experiments, however, forskolin alone was able to mimic the effects of BDNF, and STD-LTP was prevented when the postsynaptic cell was loaded with the membrane impermeable PKA inhibitor PKI 6-22. This suggests that cAMPdependent PKA may regulate intracellular calcium rise (Obrietan and van den Pol, 1997; Dunn et al., 2006), which in turn would affect BDNF release from the postsynaptic cell. The precise molecular mechanisms regulating this cascade remain to be elucidated.

In conclusion, our results show that, during postnatal development, pairing back propagating action potentials with MFGPSPs persistently enhances synaptic efficacy and brings CA3 principal cells to fire, thus providing a reliable way to convey information from granule cells to the CA3 associative network at a time when glutamatergic synapses are still poorly developed.

\section{References}

Aguado F, Carmona MA, Pozas E, Aguiló A, Martínez-Guijarro FJ, Alcantara S, Borrell V, Yuste R, Ibañez CF, Soriano E (2003) BDNF regulates spontaneous correlated activity at early developmental stages by increasing synaptogenesis and expression of the $\mathrm{K}+/ \mathrm{Cl}$ - cotransporter KCC2. Development 130:1267-1280.

Allen C, Stevens CF (1994) An evaluation of causes for unreliability of synaptic transmission. Proc Natl Acad Sci U S A 91:10380-10383.

Balena T, Woodin MA (2008) Coincident pre- and postsynaptic activity downregulates NKCC1 to hyperpolarize $\mathrm{E}(\mathrm{Cl})$ during development. Eur J Neurosci 27:2402-2412.

Banke TG, McBain CJ (2006) GABAergic input onto CA3 hippocampal interneurons remains shunting throughout development. J Neurosci 26:11720-11725.

Ben-Ari Y (2002) Excitatory action of GABA during development: the nature of the nurture. Nat Rev Neurosci 3:728-739.

Ben-Ari Y, Gaiarsa JL, Tyzio R, Khazipov R (2007) GABA: a pioneer transmitter that excites immature neurons and generates primitive oscillations. Physiol Rev 87:1215-1284.

Bi GQ, Poo MM (1998) Synaptic modifications in cultured hippocampal neurons: dependence on spike timing, synaptic strength, and postsynaptic cell type. J Neurosci 18:10464-10472.

Boulanger L, Poo MM (1999) Gating of BDNF-induced synaptic potentiation by cAMP. Science 284:1982-1984.

Caporale N, Dan Y (2008) Spike timing-dependent plasticity: a hebbian learning rule. Annu Rev Neurosci 31:25-46.

Carmona MA, Pozas E, Martínez A, Espinosa-Parrilla JF, Soriano E, Aguado F (2006) Age-dependent spontaneous hyperexcitability and impairment of GABAergic function in the hippocampus of mice lacking trkB. Cereb Cortex 16:47-63.

Cherubini E, Gaiarsa JL, Ben-Ari Y (1991) GABA: an excitatory transmitter in early postnatal life. Trends Neurosci 14:515-519.

Dan Y, Poo MM (2004) Spike timing-dependent plasticity of neural circuits. Neuron 44:23-30.

Dan Y, Poo MM (2006) Spike timing-dependent plasticity: from synapse to perception. Physiol Rev 86:1033-1048.

Debanne D, Gähwiler BH, Thompson SM (1998) Long-term synaptic plasticity between pairs of individual CA3 pyramidal cells in rat hippocampal slice cultures. J Physiol 507:237-247.

Doherty JJ, Alagarsamy S, Bough KJ, Conn PJ, Dingledine R, Mott DD
B

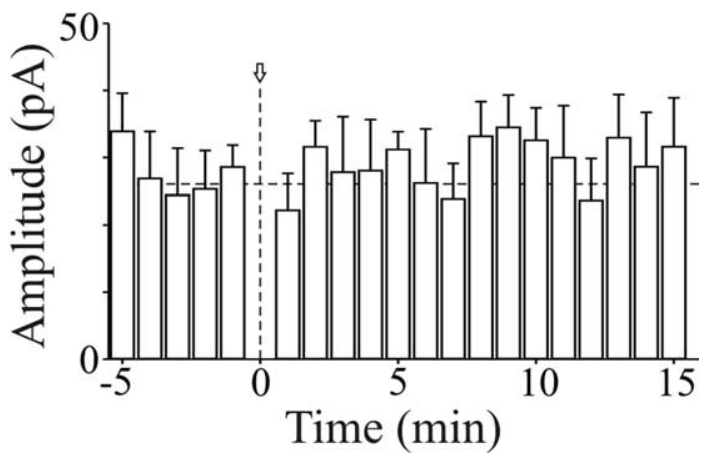

\lrcorner $10 \mathrm{pA}$

Figure 10. Pairing-induced potentiation of GPSCS was prevented by inhibiting PKA in the postsynaptic neuron. $A$, Individual and 15 min after pairing. $B$. Summary plot showing the mean amplitude of GPSCs (recorded with a patch containing PKI 6-22) evoked before and after pairing (arrows at time 0 ) as a function of time. In the presence of PKI 6-22 into the patch pipette, pairing was unable to modify MF-mediated synaptic responses. in a developmentally regulated manner in rat dentate gyrus. J Physiol 561:395-401.

Du JL, Poo MM (2004) Rapid BDNF-induced retrograde synaptic modification in a developing retinotectal system. Nature 429:878-883.

Dunn TA, Wang CT, Colicos MA, Zaccolo M, DiPilato LM, Zhang J, Tsien RY, Feller MB (2006) Imaging of cAMP levels and protein kinase A activity reveals that retinal waves drive oscillations in second-messenger cascades. J Neurosci 26:12807-12815.

Dupuy ST, Houser CR (1997) Developmental changes in GABA neurons of the rat dentate gyrus: an in situ hybridization and birthdating study. J Comp Neurol 389:402-418.

Dzhala VI, Talos DM, Sdrulla DA, Brumback AC, Mathews GC, Benke TA, Delpire E, Jensen FE, Staley KJ (2005) NKCC1 transporter facilitates seizures in the developing brain. Nat Med 11:1205-1213.

Feldman DE (2000) Timing-based LTP and LTD at vertical inputs to layer II/III pyramidal cells in rat barrel cortex. Neuron 27:45-56.

Fiumelli H, Woodin MA (2007) Role of activity-dependent regulation of neuronal chloride homeostasis in development. Curr Opin Neurobiol 17:81-86.

Fiumelli H, Cancedda L, Poo MM (2005) Modulation of GABAergic transmission by activity via postsynaptic $\mathrm{Ca} 2+$-dependent regulation of KCC2 function. Neuron 48:773-786.

Frahm C, Draguhn A (2001) GAD and GABA transporter (GAT-1) mRNA expression in the developing rat hippocampus. Brain Res Dev Brain Res 132:1-13.

Gaiarsa JL, Caillard O, Ben-Ari Y (2002) Long-term plasticity at GABAergic and glycinergic synapses: mechanisms and functional significance. Trends Neurosci 25:564-570.

Garaschuk O, Hanse E, Konnerth A (1998) Developmental profile and synaptic origin of early network oscillations in the CA1 region of rat neonatal hippocampus. J Physiol 507:219-236.

Gasparini S, Saviane C, Voronin LL, Cherubini E (2000) Silent synapses in the developing hippocampus: lack of functional AMPA receptors or low probability of glutamate release? Proc Natl Acad Sci U S A 97:9741-9746.

Goodman LJ, Valverde J, Lim F, Geschwind MD, Federoff HJ, Geller AI, Hefti F (1996) Regulated release and polarized localization of brain-derived neurotrophic factor in hippocampal neurons. Mol Cell Neurosci 7:222-238.

Gubellini P, Ben-Ari Y, Gaïarsa JL (2005) Endogenous neurotrophins are required for the induction of GABAergic long-term potentiation in the neonatal rat hippocampus. J Neurosci 25:5796-5802.

Gutiérrez R (2005) The dual glutamatergic-GABAergic phenotype of hippocampal granule cells. Trends Neurosci 28:297-303.

Gutiérrez R, Romo-Parra H, Maqueda J, Vivar C, Ramìrez M, Morales MA, Lamas M (2003) Plasticity of the GABAergic phenotype of the "glutamatergic" granule cells of the rat dentate gyrus. J Neurosci 23:5594-5598.

Haas JS, Nowotny T, Abarbanel HD (2006) Spike-timing-dependent plas- 
ticity of inhibitory synapses in the entorhinal cortex. J Neurophysiol 96:3305-3313.

Ji Y, Pang PT, Feng L, Lu B (2005) Cyclic AMP controls BDNF-induced TrkB phosphorylation and dendritic spine formation in mature hippocampal neurons. Nat Neurosci 8:164-172.

Jonas P, Major G, Sakmann B (1993) Quantal components of unitary EPSCs at the mossy fibre synapse on CA3 pyramidal cells of rat hippocampus. J Physiol 472:615-663.

Kasyanov AM, Safiulina VF, Voronin LL, Cherubini E (2004) GABAmediated giant depolarizing potentials as coincidence detectors for enhancing synaptic efficacy in the developing hippocampus. Proc Natl Acad Sci U S A 101:3967-3972.

Knüsel B, Hefti F (1992) K-252 compounds: modulators of neurotrophin signal transduction. J Neurochem 59:1987-1996.

Kuczewski N, Langlois A, Fiorentino H, Bonnet S, Marissal T, Diabira D, Ferrand N, Porcher C, Gaiarsa JL (2008a) Spontaneous glutamatergic activity induces a BDNF-dependent potentiation of GABAergic synapses in the newborn rat hippocampus. J Physiol 586:5119-5128.

Kuczewski N, Porcher C, Ferrand N, Fiorentino H, Pellegrino C, Kolarow R, Lessmann V, Medina I, Gaiarsa JL (2008b) Backpropagating action potentials trigger dendritic release of BDNF during spontaneous network activity. J Neurosci 28:7013-7023.

Kullmann DM (1993) Quantal variability of excitatory transmission in the hippocampus: implications for the opening probability of fast glutamategated channels. Proc Biol Sci 253:107-116.

Kyrozis A, Reichling DB (1995) Perforated-patch recording with gramicidin avoids artifactual changes in intracellular chloride concentration. J Neurosci Methods 57:27-35.

Lamsa K, Palva JM, Ruusuvuori E, Kaila K, Taira T (2000) Synaptic GABA(A) activation inhibits AMPA-kainate receptor-mediated bursting in the newborn (P0-P2) rat hippocampus. J Neurophysiol 83:359-366.

Leinekugel X, Medina I, Khalilov I, Ben-Ari Y, Khazipov R (1997) Ca2+ oscillations mediated by the synergistic excitatory actions of GABA(A) and NMDA receptors in the neonatal hippocampus. Neuron 18:243-255.

Lessmann V, Gottmann K, Malcangio M (2003) Neurotrophin secretion: current facts and future prospects. Prog Neurobiol 69:341-374.

Li YX, Zhang Y, Lester HA, Schuman EM, Davidson N (1998) Enhancement of neurotransmitter release induced by brain-derived neurotrophic factor in cultured hippocampal neurons. J Neurosci 18:10231-10240.

Magby JP, Bi C, Chen ZY, Lee FS, Plummer MR (2006) Single-cell characterization of retrograde signaling by brain-derived neurotrophic factor. J Neurosci 26:13531-13536.

Magee JC, Johnston D (1997) A synaptically controlled, associative signal for Hebbian plasticity in hippocampal neurons. Science 275:209-213.

Malenka RC, Nicoll RA (1999) Long-term potentiation-a decade of progress? Science 285:1870-1874.

Markram H, Lübke J, Frotscher M, Sakmann B (1997) Regulation of synaptic efficacy by coincidence of postsynaptic APs and EPSPs. Science 275:213-215.

Meyer-Franke A, Wilkinson GA, Kruttgen A, Hu M, Munro E, Hanson MG
Jr, Reichardt LF, Barres BA (1998) Depolarization and cAMP elevation rapidly recruit TrkB to the plasma membrane of CNS neurons. Neuron 21:681-693.

Mohajerani MH, Cherubini E (2005) Spontaneous recurrent network activity in organotypic rat hippocampal slices. Eur J Neurosci 22:107-118.

Mohajerani MH, Sivakumaran S, Zacchi P, Aguilera P, Cherubini E (2007) Correlated network activity enhances synaptic efficacy via BDNF and the ERK pathway at immature CA3 CA1 connections in the hippocampus. Proc Natl Acad Sci U S A 104:13176-13181.

Nagappan G, Lu B (2005) Activity-dependent modulation of the BDNF receptor TrkB: mechanisms and implications. Trends Neurosci 28:464-471.

Obrietan K, van den Pol AN (1997) GABA activity mediating cytosolic $\mathrm{Ca} 2+$ rises in developing neurons is modulated by cAMP-dependent signal transduction. J Neurosci 17:4785-4799.

Poo MM (2001) Neurotrophins as synaptic modulators. Nat Rev Neurosci 2:24-32.

Safiulina VF, Fattorini G, Conti F, Cherubini E (2006) GABAergic signaling at mossy fiber synapses in neonatal rat hippocampus. J Neurosci 26:597-608.

Salin PA, Scanziani M, Malenka RC, Nicoll RA (1996) Distinct short-term plasticity at two excitatory synapses in the hippocampus. Proc Natl Acad Sci U S A 93:13304-13309.

Sipilä ST, Schuchmann S, Voipio J, Yamada J, Kaila K (2006) The cationchloride cotransporter NKCC1 promotes sharp waves in the neonatal rat hippocampus. J Physiol 573:765-773.

Staley KJ, Mody I (1992) Shunting of excitatory input to dentate gyrus granule cells by a depolarizing GABAA receptor-mediated postsynaptic conductance. J Neurophysiol 68:197-212.

Tyzio R, Holmes GL, Ben-Ari Y, Khazipov R (2007) Timing of the developmental switch in GABA(A) mediated signaling from excitation to inhibition in CA3 rat hippocampus using gramicidin perforated patch and extracellular recordings. Epilepsia 48:96-105.

Uchigashima M, Fukaya M, Watanabe M, Kamiya H (2007) Evidence against GABA release from glutamatergic mossy fiber terminals in the developing hippocampus. J Neurosci 27:8088-8100.

Walker MC, Ruiz A, Kullmann DM (2001) Monosynaptic GABAergic signaling from dentate to CA3 with a pharmacological and physiological profile typical of mossy fiber synapses. Neuron 29:703-715.

Woodin MA, Ganguly K, Poo MM (2003) Coincident pre- and postsynaptic activity modifies GABAergic synapses by postsynaptic changes in $\mathrm{Cl}-$ transporter activity. Neuron 39:807-820.

Yasuda H, Barth AL, Stellwagen D, Malenka RC (2003) A developmental switch in the signaling cascades for LTP induction. Nat Neurosci 6:15-16.

Zhang LI, Tao HW, Holt CE, Harris WA, Poo MM (1998) A critical window for cooperation and competition among developing retinotectal synapses. Nature 395:37-44.

Zucker RS (1989) Short-term synaptic plasticity. Annu Rev Neurosci 12:1331. 